\title{
Hambatan Implementasi Surviving Sepsis Campaign Guidelines 2012 pada Pasien Anak di Rumah Sakit Rujukan Tersier
}

\author{
The Barrier of Surviving Sepsis Campaign Guideline 2012 Implementation for Children at Tertiary \\ Hospital
}

\author{
Saptadi Yuliarto, Kurniawan T Kadafi, lin TL Nugrahani, Rahmawati Aminingrum, Husnul Asariati \\ Laboratoium IImu Kesehatan Anak Fakultas Kedokteran Universitas Brawijaya Malang
}

\begin{abstract}
ABSTRAK
Tata laksana adekuat sepsis dapat memperbaiki luaran pasien. Surviving sepsis campaign (SSC) guidelines 2012 merupakan panduan internasional tata laksana sepsis berat dan syok septik, namun implementasinya dipengaruhi oleh sumberdaya dan fasilitas kesehatan. Penelitian ini mengevaluasi implementasi SSC di rumah sakit. Studi prospektif dilakukan antara Februari-Juni 2013 pada seluruh pasien usia 1 bulan-18 tahun yang memenuhi kriteria sepsis, dengan menilai penggunaan cairan resusitasi dan obat vasoaktif, waktu pemberian antibiotika, waktu pengambilan kultur, pemberian nutrisi, penggunaan ventilator, dan angka kematian. Di antara 40 pasien, 34 merupakan kasus syok septik. Seluruh pasien syok septik mendapatkan resusitasi cairan dan obat vasoaktif. Obat vasoaktif diberikan kurang dari 6 jam pada 21 pasien. Hanya 14 pasien mendapatkan antibiotika pada jam pertama, dan hanya 6 pasien dilakukan pemeriksaan kultur darah sebelum pemberian antibiotika awal. Sebanyak 28 pasien membutuhkan ventilator, namun 13 pasien tidak bisa mendapatkannya. Hal ini meningkatkan risiko mortalitas 2,1 kali $(95 \%$ IK 1,2; 3,7). Saat perawatan di unit intensif, 27 pasien mendapatkan nutrisi pada 6-24 jam pertama, namun sebagian besar ( 32 pasien) mendapatkan kalori kurang dari $80 \%$ dalam 48 jam pertama yang meningkatkan risiko mortalitas 3 kali $(95 \%$ IK 1,1; 8,2). Mortalitas terjadi pada 24 pasien. Hal ini menunjukkan adanya hambatan pelaksanaan SSC guidelines 2012 dalam hal pemberian antibiotika, pemeriksaan kultur darah, penggunaan ventilator, dan pemberian nutrisi adekuat. Ketidaktersediaan ventilator dan terapi nutrisi inadekuat meningkatkan risiko mortalitas.
\end{abstract}

Kata Kunci: Antibiotika, kultur darah, mortalita, nutrisi, sepsis, ventilator

\begin{abstract}
The adequate sepsis management are likely improve patient's outcome. Surviving sepsis campaign (SSC) 2012 is an international guideline for management of severe sepsis and septic shock, however its implementation is depend on health facilities and resources. This study evaluates implementation of the guideline in hospital. Prospective study was conducted in February-June 2013, included pediatric patient 1 month-18 years old fulfilled sepsis criteria at Saiful Anwar General Hospital. The management of fluid resuscitation and vasoactice drug, time to perform antibiotics and blood culture examination, nutrition, mechanical ventilation, and mortality rate were observed. Of 40 patients, 34 were septic shock. All septic shock patients got fluid resuscitation and vasoactive drugs. In 21 patients, vasoactive drugs were given at the first 6 hours. Only 14 patients were given antibiotics at the first 1-hour, and only 6 were performed blood culture examination. Twenty-eight patients need mechanical ventilation, yet 13 could not receive it, which increased the mortality risk 2,1 times (95\% CI 1,2; 3,7). In PICU, 27 patients received nutritional support at the 6-24 hours, however most (32 patients) received calories less than $80 \%$ at the first 48 hours, with mortality risk 3 times higher $(95 \% \mathrm{Cl} 1,1 ; 8,2)$. Mortality occurred in 24 patients. This study showed the obstacles in implementing SSC guideline 2012 for antibiotics administraton, blood culture examination, mechanical ventilation, and adequate nutrition in severe sepsis and septic shock. Inavailability of mechanical ventilation and inadequate nutrition increased the mortality risk.
\end{abstract}

Keywords: Antibiotics, blood culture, mechanical ventiliation, mortality, nutrition, sepsis

Jurnal Kedokteran Brawijaya, Vol. 28, No. 1, Februari 2014; Korespondensi: Saptadi Yuliarto. Laboratorium IImu Kesehatan Anak Fakultas Kedokteran Universitas Brawijaya Malang, Jl. Veteran Malang Tel. (0341) 567192 Email: dr.saptadiyuliarto@gmail.com 


\section{PENDAHULUAN}

Sepsis adalah respon inflamasi sistemik akibat infeksi yang dapat berlanjut menjadi sepsis berat dan syok septik. Sepsis berat dan syok septik merupakan masalah kesehatan dengan angka kematian pada anak sebesar 60$80 \%$ per tahun. Kecepatan dan ketepatan terapi yang diberikan pada jam pertama dapat memperbaiki luaran pasien $(1,2)$.

Surviving sepsis campaign (SSC) 2012 merupakan panduan internasional tata laksana sepsis berat dan syok septik, dengan beberapa kekhususan rekomendasi untuk pasien anak. SSC bundles merekomendasikan dalam 3 jam pertama harus dilakukan: (1) pemberian resusitasi cairan sampai dengan $20 \mathrm{ml} / \mathrm{kg}$ selama 5-10 menit, (2) pengukuran kadar laktat, (3) pemeriksaan kultur darah sebelum pemberian antibiotika, dan (4) pemberian antibiotika spektrum luas; dilanjutkan dalam 6 jam harus dilakukan (1) pemberian inotropik atau vasopressor dan (2) pengukuran tekanan vena sentral dan saturasi oksigen vena sentral. Selain itu, nutrisi enteral direkomendasikan untuk diberikan sebagai nutrisi awal (early feeding) dalam 48 jam pada pasien sepsis (2).

Sebagian besar rekomendasi telah disesuaikan untuk pasien di intensive care unit (ICU) dan non-ICU, namun keterbatasan sumber daya dan fasilitas di beberapa institusi atau negara menyebabkan adanya hambatan dalam pelaksanaannya. Oleh karena itu, diperlukan evaluasi dan umpan balik implementasi pada rumah sakit untuk memperbaiki panduan tersebut sehingga dapat mengurangi mortalitas dan morbiditas sepsis di seluruh dunia. Tujuan penelitian ini adalah untuk menggambarkan implementasi dan hasil SSC guidelines 2012 pada pasien anak di salah satu rumah sakit umum di Malang.

\section{METODE}

Dilakukan penelitian prospektif pada bulan Februari sampai Juni 2013 pada seluruh pasien anak (usia 1 bulan18 tahun) di Instalasi Gawat Darurat (IGD), High Care Unit (HCU), dan Pediatric Intensive Care Unit (PICU) rumah sakit, yang memenuhi kriteria sepsis sesuai konsensus pediatrik internasional (3). Variabel yang diamati adalah penggunaan cairan resusitasi dan obat vasoaktif, waktu pemberian antibiotika, waktu pengambilan kultur darah, pemberian nutrisi, penggunaan ventilator, dan angka kematian. Penggunaan cairan resusitasi meliputi jenis cairan (kristaloid atau koloid) dan jumlah rerata cairan yang digunakan sampai pasien membaik atau sampai terjadi fluid overload. Penggunaan obat vasoaktif meliputi jenis obat dan waktu pemberian. Waktu pemberian antibiotika dan pengambilan kultur darah merupakan waktu sejak pasien datang di IGD sampai dilakukan tindakan tersebut. Pemberian nutrisi meliputi waktu pemberian sejak pasien datang, rute pemberian nutrisi awal, dan persentase kalori yang diberikan terhadap kebutuhan kalori (berdasarkan penghitungan resting energy expenditure metode Schofield) $(1,4)$. Penggunaan ventilator meliputi jumlah pasien yang memerlukan dan yang mendapat dukungan ventilasi mekanik. Angka kematian merupakan jumlah pasien yang meninggal selama pengamatan atau selama pasien dirawat di rumah sakit. Seluruh variabel tersebut disajikan secara deskriptif dalam bentuk persentase pada tabel. Waktu pemberian antibiotika, penggunaan ventilator, dan pemberian nutrisi dianalisis korelasinya dengan angka kematian menggunakan uji chi-square (IK $95 \%, p>0,05$ ).

\section{HASIL}

\section{Karakteristik Subjek}

Selama pengamatan didapatkan 40 subjek dengan $65 \%$ (26/40) berusia kurang dari 1 tahun. Sebanyak 85\% (34/40) adalah pasien syok septik dan $10 \%(4 / 40)$ adalah pasien sepsis berat. Angka mortalitas sebesar $60 \%$ (24/40) pasien (Tabel 1).

Tabel 1. Karakteristik subjek

\begin{tabular}{lc}
\hline \multicolumn{1}{c}{ Variabel } & Populasi penelitian (N=40) \\
\hline Usia, $\mathrm{n}(\%)$ & $26(65)$ \\
1 bulan -1 tahun & $4(10)$ \\
$2-5$ tahun & $6(15)$ \\
6-12 tahun & $4(10)$ \\
13-18 tahun & \\
Jenis kelamin, $\mathrm{n}(\%)$ & $26(65)$ \\
$\quad$ Laki-laki & $14(35)$ \\
Perempuan & \\
Diagnosis, $\mathrm{n}(\%)$ & $2(5)$ \\
Sepsis & $4(10)$ \\
Sepsis berat & $34(85) 24(60)$ \\
Syok septikMortalitas, $\mathrm{n}(\%)$ & \\
\hline
\end{tabular}

\section{ImplementasiSSC Guidelines}

Sebanyak 85\% (34/40) pasien adalah pasien syok septik yang memerlukan resusitasi cairan. Kristaloid digunakan sebagai pilihan awal cairan resusitasi pada 78,8\% (28/34) pasien $(5,6)$. Seluruh pasien syok septik mengalami syok refrakter cairan (membutuhkan obat vasoaktif) dengan rerata volume cairan yang diberikan adalah $29,1 \mathrm{ml} / \mathrm{kg}$. Pemberian obat vasoaktif 85,3\% (29/34) diberikan kurang dari 6 jam, yang sebagian besar menggunakan golongan inotropik (dopamin, dobutamin, dan epinefrin). Antibiotika diberikan setelah 1 jam pada sebagian besar $(65 \%, 26 / 40)$ pasien dan hanya $15 \%(6 / 40)$ yang kultur darahnya diambil sebelum pemberian antibiotika. Sebanyak $70 \%(28 / 40)$ pasien membutuhkan ventilasi mekanik, namun 46,4\% $(13 / 28)$ tidak bisa mendapatkannya. Seluruh pasien mendapatkan dukungan nutrisi dan 67,5\% (27/40) diberikan dalam 24 jam. Rute enteral hanya dapat diberikan pada $42,5 \%(17 / 40)$ pasien. Dalam 48 jam, 80\% (32/40) hanya mendapatkan kalori kurang dari $80 \%$ kebutuhan (Tabel 2). Fakta ini menunjukkan bahwa implementasi SSC belum dapat dilakukan pada $100 \%$ kasus terutama pada pemeriksaan kultur, penggunaan ventilator mekanik bagi yang membutuhkan dan kecukupan nutrisi.

Tabel 2. Implementasi SSC guidelines

\begin{tabular}{lc}
\hline \multicolumn{1}{c}{ Variabel } & Populasi penelitian $(\mathbf{N}=\mathbf{4 0})$ \\
\hline Resusitasi cairan, $\mathrm{n}(\%)$ & $34(85)$ \\
Kristaloid & $28(78,8)$ \\
Koloid & $6(21,2)$ \\
Volume cairan resusitasi $(\mathrm{ml})$, rerata & 29,1 \\
Obat vasoaktif, $\mathrm{n}(\%)$ & $34(85)$ \\
Dopamin & $3(8,8)$ \\
Dobutamin & $11(32,4)$ \\
Epinefrin & $1(2,9)$ \\
Norepinefrin & $1(2,9)$ \\
Kombinasi & $18(52,9)$ \\
\end{tabular}


Tabel 2 . Implementasi SSC guidelines (Lanjutan)

\begin{tabular}{|c|c|}
\hline Variabel & $\begin{array}{c}\text { Populasi } \\
\text { penelitian }(\mathrm{N}=40)\end{array}$ \\
\hline \multicolumn{2}{|l|}{ Waktu pemberian obat vasoaktif, n (\%) } \\
\hline$<6$ jam & $29(85,3)$ \\
\hline$\geq 6$ jam & $5(14,7)$ \\
\hline $\begin{array}{l}\text { Pemberian antibiotika dan pengambilan kultur } \\
\text { darah, } n(\%) \text { Waktu pemberian antibiotika, } n(\%)\end{array}$ & $40(100)$ \\
\hline$\leq 1 \mathrm{jam}$ & $14(35)$ \\
\hline$>1$ jam & $26(65)$ \\
\hline \multicolumn{2}{|l|}{ Waktu pengambilan kultur darah, $\mathrm{n}(\%)$} \\
\hline Sebelum pemberian antibiotika & $6(15)$ \\
\hline Setelah pemberian antibiotika & $34(85)$ \\
\hline Memerlukan ventilasi mekanik, n (\%) & $28(70)$ \\
\hline Tidak Mendapatkan ventilasi mekanik & $13(46,5)$ \\
\hline Mendapatkan ventilasi mekanik & $15(53,5)$ \\
\hline Pemberian nutrisi, n (\%) & $40(100)$ \\
\hline \multicolumn{2}{|l|}{ Waktu pemberian, n (\%) } \\
\hline$\leq 24$ jam & $27(67,5)$ \\
\hline >24 jam & $13(32,5)$ \\
\hline \multicolumn{2}{|l|}{ Pemberian kalori dalam 48 jam, n (\%) } \\
\hline$<80 \%$ kebutuhan & $32(80)$ \\
\hline$\geq 80 \%$ kebutuhan & $8(20)$ \\
\hline \multicolumn{2}{|l|}{ Rute pemberian nutrisi dalam 48 jam, n (\%) } \\
\hline Enteral & $17(42,5)$ \\
\hline Parenteral & $23(57,5)$ \\
\hline
\end{tabular}

\section{Hubungan penerapan SSC dengan Mortalitas}

Pasien yang membutuhkan ventilasi mekanik namun tidak mendapatkannya (berurutan: $R R=2,1$ [95\% IK 1,2; 3,7]) dan pasien yang mendapatkan kalori kurang dari $80 \%$ kebutuhan dalam 48 jam pertama (RR=3,0 [95\% IK 1,1; $8,2]$ ), mengalami peningkatan risiko kematian dan. Waktu pemberian antibiotika tidak berhubungan dengan angka kematian $(p=0,49)$ (Tabel 3). Analisis ini menunjukkan bahwa ketidaktepatan dalam implementasi SSC terutama dalam ketersediaan ventilasi mekanis dan kecukupan kalori pada 48 jam pertama meningkatkan risiko kematian.

Tabel 3. Hubungan implementasi dengan mortalitas

\begin{tabular}{lcc}
\hline \multicolumn{1}{c}{ Variabel } & Risiko Relatif (RR) & $\boldsymbol{p}$ \\
\hline Waktu pemberian antibiotka & $1,8(95 \%$ IK 0,$5 ; 7,1)$ & 0,49 \\
Ketidaktersediaan ventilasi mekanik & $2,1(95 \%$ IK 1,$2 ; 3,7)$ & 0,002 \\
Kalori <80\% pada 48 jam pertama & $3,0(95 \%$ IK 1,1; 8,2) & 0,002 \\
\hline
\end{tabular}

\section{DISKUSI}

Penelitian ini menunjukkan adanya hambatan implementasi SSC guidelines 2012, yaitu keterlambatan pemberian antibiotika lebih dari 1 jam, keterlambatan pengambilan kultur darah, ketidaktersediaan ventilasi mekanik, pemberian kalori inadekuat, dan hambatan pemberian nutrisi enteral. Hambatan implementasi ini berkaitan dengan angka mortalitas sebesar $60 \%$ yang disebabkan oleh ketidaktersediaan ventilasi mekanik yang meningkatkan risiko kematian 2,1 kali dan pemberian kalori inadekuat yang meningkatkan risiko kematian 3 kali.Pemberian antibiotika dalam waktu 1 jam pertama bertujuan untuk mengeradikasi bakteri penyebab dan menghentikan proses infeksi, dan hal ini berkaitan dengan meningkatnya angka kesintasan sebesar $79 \%$. Setiap 1 jam keterlambatan akan menurunkan kesintasan 7,6\% dan mortalitas meningkat sebesar 1,67 kali $(95 \%$ IK 1,12; 2,48) $(7,8)$. Pada penelitian ini, sebagian besar pasien mendapatkan antibiotika setelah 1 jam, namun tidak meningkatkan angka kematian. Hal ini sama dengan penelitian oleh Gaieski yang menyatakan tidak ada hubungan antara waktu pemberian antibiotika dan kematian (9). Penyebabnya kemungkinan adalah dilakukannya resusitasi cairan dan pemberian obat vasoaktif secara cepat dan tepat pada 6 jam pertama. Selain itu, sebagian besar pasien merupakan pasien rujukan yang kemungkinan telah memperoleh antibiotika di rumah sakit perujuk.

Pengambilan kultur darah bertujuan untuk memperoleh data mikroorganisme penyebab sepsis dan sensitivitasnya terhadap antibiotika agar dapat dilakukan pemberian terapi definitif. Untuk meningkatkan akurasi hasil, pengambilannya dilakukan sebelum pemberian antibiotika. Permasalahan yang sering terjadi adalah sulitnya pengambilan darah akibat vena yang kolaps pada pasien syok septik, padahal antibiotika harus diberikan dalam waktu 1 jam baik secara intravena atau intramuskular (2). Hal inilah yang mungkin menyebabkan keterlambatan sebagian besar pengambilan kultur darah pada penelitian ini.

Acute Lung Injury (ALI) dan Acute Respiratory Distress Syndrome (ARDS) 30-40\% disebabkan oleh sepsis dengan mortalitas sebesar $26-32 \%(10,11)$. Sebanyak $70 \%$ pasien mengalami gagal nafas yang membutuhkan dukungan ventilasi mekanik, serupa dengan penelitian oleh Jaramillo-Bustamante yang menyatakan $68 \%$ pasien sepsis membutuhkan ventilasi mekanik (12). Karena ketidakseimbangan antara jumlah pasien gagal nafas dengan ventilasi mekanik yang tersedia, $46,4 \%$ pasien tidak mendapatkan dukungan ventilasi mekanik sehingga menyebabkan $71,4 \%$ kematian pada seluruh pasien gagal nafas. Ketidaktersediaan ventilasi mekanik berisiko meningkatkan kematian sebanyak 2,1 kali dan menyebabkan mortalitas pasien gagal nafas pada penelitian ini lebih tinggi dibandingkan penelitian sebelumnya $(10,11)$.

Kecepatan resusitasi menanggulangi syok merupakan faktor terpenting karena dapat meningkatkan angka kesintasan mencapai 96\% dan kemungkinan kesintasan 9 kali lebih baik $(2,5,6)$. Pada penelitian ini, pemberian cairan resusitasi dan obat vasoaktif telah dilakukan sesuai dengan SSC bundles berupa cairan kristaloid atau koloid 20-60 $\mathrm{ml} / \mathrm{kg}$ dalam 5-10 menit dan pemberian obat-obatan vasoaktif dalam 6 jam pertama.

Pada pasien kritis, termasuk sepsis, rute enteral direkomendasikan untuk segera diberikan karena dapat mencegah atrofi mukosa, menjaga flora normal usus, menjaga sistem enzim enterohepatik, dan menurunkan angka kematian $(2,13,14)$. Pada kenyataannya, hal ini sulit dilakukan karena adanya disfungsi saluran cerna, intoleransi minum, resusitasi berkepanjangan, restriksi cairan, tindakan invasif, atau rendahnya prioritas terapi nutrisi $(15,16)$. Akibatnya, hanya $67,5 \%$ pasien mendapatkan nutrisi dalam 24 jam dan hanya $42,5 \%$ yang mendapatkan nutrisi enteral pada 48 jam pertama. Hasil ini serupa dengan penelitian sebelumnya, yaitu hanya $40-$ $60 \%$ nutrisi enteral dapat diberikan dalam 2 hari pertama dan $80 \%$ pada hari ke-7 (17). 
Kesulitan pemberian nutrisi juga mengakibatkan rendahnya kalori yang diterima pasien sepsis, yaitu hanya $80 \%$ pasien menerima $80 \%$ kalori dalam 48 jam. Penelitian lain melaporkan hasil yang sama, yaitu dalam 2 hari, rerata kalori yang bisa dicapai kurang dari $80 \%$ dan dalam 5 hari rerata kalori dapat $100 \%$ tercapai (17). Pemberian nutrisi inadekuat atau hipokalorik tersebut meningkatkan risiko infeksi, lama rawat inap, lama pemakaian antibiotika, lama penggunaan ventilasi mekanik, dan mortalitas $(14,18)$. Penelitian ini menunjukkan nutrisi inadekuat meningkatkan risiko kematian 3 kali, serupa dengan hasil penelitian sebelumnya, yaitu peningkatan asupan nutrisi dari 33\% menjadi 66\% menurunkan angka kematian 0,27 kali $(95 \%$ IK 0,11; 0,67) (14).

Jumlah sampel 40 pasien (minimum sampel 60 untuk $\alpha=0,05)$ merupakan salah satu kelemahan penelitian, namun dengan jumlah sampel yang ada, penelitian ini masih menghasilkan tingkat kepercayaan 85-90\% $(\alpha=0,10-0,15)$ sehingga masih representatif untuk dijadikan studi pendahuluan. Keterbatasan lain adalah tidak dilakukannya pengendalian faktor perancu (usia,

\section{DAFTAR PUSTAKA}

1. Kissoon N, Carcillo JA, Espinosa V, et al. World Federation of Pediatric Intensive Care and Critical Care Societies: Global Sepsis Initiative. Pediatric Critical Care Medicine. 2011; 12(5): 494-503.

2. Dellinger RP, Levy MM, Rhodes $A$, et al. Surviving Sepsis Campaign: International Guidelines for Management of Severe Sepsis and Septic Shock: 2012. Critical Care Medicine. 2013; 41(2): 580-637.

3. Goldstein B, Giroir B, and Randolph A. International Pediatric Sepsis Consensus Conference: Definitions for Sepsis and Organ Dysfunction in Pediatrics. Pediatric Critical Care Medicine. 2005; 6(1): 2-8.

4. Havalad S, Quaid MA, and Sapiega V. Energy Expenditure lin Children with Severe Head Injury: Lack of Agreement between Measured and Estimated Energy Expenditure. Nutrition in Clinical Practice. 2006; 21(2): 175-81.

5. Han YY, Carcillo JA, Dragotta MA, et al. Early Reversal of Pediatric-Neonatal Septic Shock by Community Physicians is Associated with Improved Outcome. Pediatrics. 2003; 112(4): 793-799.

6. Carcillo JA, Han K, and Orr RA. Goal-Directed Management of Pediatric Shock in the Emergency Department. Clinical Pediatric Emergency Medicine. 2007; 8(3): 165-75.

7. Kumar A, Roberts D, Wood KE, et al. Duration of Hypotension Before Initiation of Effective Antimicrobial Therapy is the Critical Determinant of Survival in Human Septic Shock. Critical Care Medicine. 2006; 34(6): 1589-1596.

8. Corey AL and Snyder S. Antibiotics in 30 Minutes or Less for Febrile Neutropenic Patients: A Quality Control Measure in a New Hospital. Journal of Pediatric Oncology Nursing. 2008; 25(4): 208-212.

9. Gaieski DF, Mikkelsen ME, Band RA, et al. Impact of Time to Antibiotics on Survival in Patients with Severe Sepsis or Septic Shock in Whom Early Goal-Directed Therapy was Initiated in the Emergency Department. Critical Care Medicine. 2010; 38(4): 1045-1053. tingkat keparahan penyakit, status nutrisi, penyakit penyerta, riwayat pengobatan sebelumnya) dalam analisis kematian. Hal ini sesuai dengan kondisi klinis nyata yaitu adanya keterlibatan multifaktor sebagai penyebab mortalitas. Selain itu, penellitan ini menunjukkan risiko relatif (RR) variabel terhadap kematian yang serupa dengan berbagai penelitian sebelumnya. Kelemahan berikutnya adalah subjek penelitian hanya diambil dari 1 rumah sakit (RS) dengan kondisi yang mungkin berbeda dengan RS lain. Tempat penelitian merupakan salah satu RS rujukan propinsi. Apabila pada rumah sakit rujukan Propinsi terdapat hambatan implementasi SSC guideline, hambatan serupa dapat terjadi pada rumah sakit setipe bahkan hambatan lebih besar dimungkinkan terjadi pada rumah sakit denga tipe lebih kecil (18).

Hasil penelitian ini menunjukkan adanya hambatan pelaksanaan SSC guidelines 2012 dalam hal pemberian antibiotika, pemeriksaan kultur darah, penggunaan ventilator, dan pemberian nutrisi adekuat. Hambatan tersebut terutama pada ketidaktersediaan ventilator dan terapi nutrisi inadekuat meningkatkan risiko mortalitas.

10. López-Fernández $\mathrm{Y}$, Azagra $\mathrm{AM}$, de la Oliva $\mathrm{P}$, et al. Pediatric Acute Lung Injury Epidemiology and Natural History Study: Incidence and Outcome of the Acute Respiratory Distress Syndrome in Children. Critical Care Medicine. 2012; 40(12): 3238-3245.

11. Zhu YF, Xu F, Lu XL, et al. Mortality and Morbidity of Acute Hypoxemic Respiratory Failure and Acute Respiratory Distress Syndrome in Infants and Young Children. Chinese Medical Journal (English Edition). 2012; 125(13): 2265-2271.

12. Jaramillo-Bustamante JC, Marín-Agudelo A, Fernández-Laverde $M$, and Bareño-Silva J. Epidemiology of Sepsis in Pediatric Intensive Care Units: First Colombian Multicenter Study. Pediatric Critical Care Medicine. 2012; 13(5): 501-508.

13. Agus MS and Jaksic T. Nutritional Support in the Critically III Child. Current Opinion in Pediatrics. 2002; 14(4): 470-481.

14. Mehta NM, Bechard LJ, Cahill N,et al. Nutritional Practices And Their Relationship To Clinical Outcomes In Critically III Children-An International Multicenter Cohort Study. Critical Care Medicine. 2012; 40(7): 2204-2211.

15. Rogers EJ, Gilbertson HR, Heine RG, and Henning R. Barriers to Adequate Nutrition in Critically III Children. Nutrition Journal. 2003; 19(10): 865-868.

16. Beck $A M$, Balknäs UN, Fürst $P$, et al. Food and Nutritional Care in Hospitals: How to Prevent Undernutrition Report and Guidelines from the Council of Europe. Clinical Nutrition. 2001; 20(5): 455-460.

17. de Neef M, Geukers VG, Dral A, Lindeboom R, Sauerwein HP, and Bos AP. Nutritional Goals, Prescription and Delivery in a Pediatric Intensive Care Unit. Clinical Nutrition. 2008; 27(1): 65-71.

18. Villet $\mathrm{S}$, Chiolero RL, Bollmann MD, et al. Negative Impact Of Hypocaloric Feeding And Energy Balance On Clinical Outcome In ICU Patients. Clinical Nutrition. 2005; 24(4): 502-509. 